\section{Exposure to second-hand smoke and reproductive outcomes depending on maternal asthma}

\author{
Jordi Sunyer*,\#,ף,+, Raquel Garcia-Esteban*,+, Ane Miren Castilla ${ }^{\S}$, Juan \\ José Aurrekoetxea ${ }^{f}$, Carmen Iñiguez ${ }^{+, * *}$, Adonina Tardón ${ }^{+, \# \#}$, Mercedes Espada ${ }^{+, \S}$, \\ Aitana Lertxundi ${ }^{f}$, Leda Chatzi ${ }^{\oplus \uparrow}$, Marisa Rebagliato** and Manolis Kogevinas*,\#,+,++ \\ on behalf of the INMA project
}

ABSTRACT: Tobacco consumption and exposure to second-hand smoke (SHS) are associated with reduced birth weight. One issue that has not been clarified previously is that of the potential higher risk of this outcome in mothers with asthma. We assessed the role of prenatal maternal tobacco use and SHS on reproductive outcomes and assessed the interaction with maternal history of asthma.

Data was collected from the INMA study, a maternal birth cohort selected from the general population established in Spain in 2002. We measured cotinine at the 32nd week of pregnancy in 2,219 females. Diagnosed maternal asthma was self-reported during pregnancy.

$35 \%$ of mothers reported not being exposed to smoking or SHS during pregnancy. Active smoking (i.e. self-reported or cotinine $>50 \mathrm{ng} \cdot \mathrm{mL}^{-1}$ ) was related to a $134 \mathrm{~g}$ decrease in birth weight and a relative risk of 1.8 for small for gestational age and fetal growth restriction. These results were not modified by maternal asthma. Maternal asthma had a similar frequency in all exposure groups. Non SHS-exposed females had the lowest prevalence of asthma. SHS (i.e. cotinine 20-50 $\mathrm{ng} \cdot \mathrm{mL}^{-1}$ ) decreased birth weight by $32 \mathrm{~g}$ among those without maternal asthma, but these differences were not statistically significant $(95 \% \mathrm{Cl}-88.76-24.76)$. Maternal asthma did not promote these effects.

Maternal history of asthma did not modify the effects of smoking on reproductive outcomes in a cohort sampled from the general population.

KEYWORDS: Asthma, birth weight, cotinine, second-hand smoke, small for gestational age

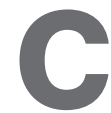
igarette smoking in females is highly prevalent in countries in southern Europe [1]. The 2006 law for smoking prevention in Spain banned smoking in workplaces and public spaces, with the exemption of bars and restaurants [2]. This exemption was only removed in 2011. In general, second-hand smoke (SHS) is difficult to prevent in Spain, even during pregnancy. The effects of SHS on offspring are not fully understood [3].

Many studies have confirmed that tobacco consumption is associated with reduced birth weight [4]. The reproductive effects of SHS are less well known. Several studies have shown a dosedependent effect of log cotinine on mean birth weight [5-9]. These studies indicate that SHS can lead to measurable levels of cotinine in the mother, and this can affect birth weight, although misreporting of active smoking could not be ruled out. In addition, the small differences in birth weight (35-87 g) between infants born to non-smoking females exposed and unexposed to SHS could be due to chance [7-9].

An issue that has not yet been solved is the reproductive effect of smoking among subgroups, in particular the potentially higher risk of smoking among asthmatic mothers. Females with asthma had a higher rate of low birth weight babies and preterm delivery than those without asthma $[10,11]$. The largest prospective study conducted in pregnant females with asthma did not find a significant risk of SHS on fetal growth abnormalities [12].

Our aim was to assess the role of SHS on reproductive outcomes at the third trimester of gestation and, in particular, to assess its interaction with asthma in a prospective study from the general
AFFILIATIONS

*Centre for Research in Environmental Epidemiology (CREAL),

${ }^{\#}$ Municipal Institute of Medical Research, and

-Universitat Pompeu Fabra, ${ }^{+}$CIBER Epidemiologia y Salud Pública (CIBERESP), Barcelona, ${ }^{\S}$ Departamento de Sanidad Gobierno Vasco, Laboratorio Normativo de Salud Pública, and

fUniversity of Basque Country, UPV/ EHU, Bilbao,

**Public Health Research Institute, Valencia, and

\#\#Universidad de Oviedo, Oviedo, Spain.

"Dept of Social Medicine, Faculty of Medicine, University of Crete,

Heraklion, and

${ }^{++}$School of Public Health, Athens, Greece.

CORRESPONDENCE

J. Sunyer

CIBER Epidemiologia y Salud Pública (CIBERESP)

Doctor Aigüader 88

Barcelona

08003

Spain

E-mail: jsunyer@creal.cat

Received:

May 302011

Accepted after revision:

Oct 262011

First published online:

Feb 092012 
population in southern Europe: the INMA study is a collaborative mother and child cohort that was established in Spain in 2003 [13].

\section{METHODS}

\section{Study population}

Data were obtained prospectively from pregnant females enrolled in the INMA study from four areas in Spain: Asturias and Gipuzkoa in the Basque Country, and Valencia and Sabadell in Catalonia. All pregnant females were recruited at their first routine antenatal care visit. The recruitment period was from May 2004 to June 2007 in Asturias, from April 2006 to January 2008 in Gipuzkoa, from July 2004 to July 2006 in Sabadell, and from November 2003 to June 2005 in Valencia. Questionnaires regarding smoking and SHS, health behaviour, socio-demographic characteristics, pregnancy history and other factors were administered by trained interviewers at recruitment, during the third trimester and at delivery. 2,644 females agreed to participate and met the inclusion criteria: aged $\geqslant 16$ yrs; singleton pregnancy; and not following any programme of assisted reproduction. We included only those females followed through to birth $(n=2,506)$, for whom information on reproductive outcomes were available $(n=2,481)$, and for whom urinary cotinine levels were assayed at the 32nd week of gestation $(n=2,289)$, yielding a total of $2,219(88 \%)$ eligible participants. Non-participants in this study did not differ from participants in any socio-demographic factor, smoking status or in SHS behaviour $(\mathrm{p}>0.35)$. The study was approved by the ethical committee of the Institut Municipal d'Investigació Mèdica of Barcelona, Spain, and by the ethical committees of the hospitals involved in the study.

\section{Reproductive outcomes}

Anthropometric measurement data were obtained from hospital delivery records and medical records, with the exception of birth length and head circumference data in the INMA cohort; these were measured by a nurse using standard protocols and instruments upon arrival of the newborn at the hospital ward, within $12 \mathrm{~h}$ of delivery. Gestational age was based on the interval between the last menstrual period and the date of delivery for $88 \%$ of the participants. When the menstrual estimate of gestational age was inconsistent by $\geqslant 7$ days with the ultrasound measurement taken in the first trimester of pregnancy $(12 \%)$, a quadratic regression formula describing the relationship between crown-rump length and gestational age was used instead [14]. Small for gestational age (SGA) was defined as an infant with a birth weight below the 10th percentile according to its gestational age from sex-specific Spanish reference tables.

A customised definition of restricted fetal growth was developed by taking into account constitutional characteristics of the neonates $[15,16]$. Maternal and newborn characteristics considered a priori were: gestational age (in weeks); maternal and paternal height (in $\mathrm{cm}$ ) and age (in yrs); maternal prepregnancy weight (in $\mathrm{kg}$ ); primiparous mother; ethnicity of mother; and infant sex. Gestational age and infant sex were considered as possible modifiers. A multivariable fractional polynomial linear regression model was used to predict birth weight, allowing polynomial terms for continuous variables in the linear regression models [16]. The model with the minimum deviance (i.e. best fit) was retained as the final model, and included gestational age, infant sex, maternal and paternal height, pre-pregnancy weight, and parity as covariates.

A neonate was defined as having fetal weight growth restriction (FwGR) if actual birth weight fell below the 10th percentile of the predicted birth weight distribution. Similar models were used to define neonates with fetal length growth restriction (FlGR) if actual birth length fell below the 10th percentile of the predicted birth weight distribution, and to define neonates with fetal head circumference growth restriction (FhcGR) if actual birth length fell below the 10th percentile of the predicted birth head circumference.

\section{Urinary cotinine level measurement}

Levels of cotinine, the major proximate metabolite of nicotine, have been widely used as a biomarker of tobacco exposure. These were determined in urine samples. Urine was collected at week 32 of pregnancy at the time of the smoking history interview. The method used was a competitive enzyme immunoassay (COTININE MICRO-PLATE EIA; Ora Sure Technologies Inc., Bethlehelm, PA, USA) adapted to urine using 0, 2.5, 10 and $50 \mathrm{ng} \cdot \mathrm{mL}^{-1}$ calibrators (Bio-Rad, Bethlehelm, PA, USA). A validity study showed a limit of quantification of $4.0 \mathrm{ng} \cdot \mathrm{mL}^{-1}$, reliability of $7 \%$ and reproducibility of $10 \%$ based on the certified reference material (EPA/NIST 8444) [17].

\section{Maternal asthma}

Maternal asthma status was based on the question: "have you ever been diagnosed with asthma?".

\section{Smoking and SHS exposure groups}

Smoking and SHS were defined based on both urine cotinine levels and on smoking history, which were assessed at the 32nd week of pregnancy. The cut-off used for cotinine levels was that reported as most sensitive for the identification of active smoking (i.e. $50 \mathrm{ng} \cdot \mathrm{mL}^{-1}$ ) [18] in order to eliminate any misreporting of smoking in the analysis of the role of SHS. Furthermore, self-reported SHS was classified according to the place of exposure after excluding those with levels $>50 \mathrm{ng} \cdot \mathrm{mL}^{-1}$. Given that the place of exposure most commonly reported was "at home", two categories were used. One category was created for those exposed at home either alone or in addition to other places. A second category was created for those not exposed at home but who were exposed in other places (65\% reported being exposed in bars or similar, $22 \%$ at work and the other $3 \%$ in other places). A third category was created for those never reporting SHS.

\section{Potential confounders}

Potential confounders included characteristics that have an established or potential association with preterm birth and fetal growth restriction, these were as follows. 1) Maternal and paternal age. 2) Maternal and paternal education: low: $\leqslant 6 \mathrm{yrs}$ of school education; medium: $\leqslant 12$ yrs of school education; high: university or technical college degree. 3) Maternal and paternal social class were defined as three occupational categories based on their current or most recent occupation (I+II, III or $\mathrm{IV}+\mathrm{V})$, following a widely used Spanish adaptation of the British classification system [19]. 4) Maternal pre-pregnancy weight $(\mathrm{kg})$. 5) Maternal pre-pregnancy and paternal body mass index $\left(\mathrm{kg} \cdot \mathrm{m}^{-2}\right)$. 6) Weight gain during pregnancy $(\mathrm{kg})$. 
7) Maternal smoking during pregnancy (yes/no). 8) Parity (primiparous or multiparous). 9) Infant sex (male or female).

\section{Statistical analysis}

The primary outcome variables of interest were birth weight, birth length, head circumference, SGA and fetal growth restriction. Given that results with gestational age and FwGR were very similar, the associations for the latter were not reported. The primary exposures of interest were cotinine levels and categories of SHS. Cotinine levels were treated both as continuous and categorical variables. Categories were based on the limit of detection cut-off as the lowest category (i.e. $\left.4 \mathrm{ng} \cdot \mathrm{mL}^{-1}\right)$, the level of active smoking as defined previously, and an intermediate level of $20 \mathrm{ng} \cdot \mathrm{mL}^{-1}$ that approaches the median among those with levels $>4 \mathrm{ng} \cdot \mathrm{mL}^{-1}$. The third variable of interest was maternal asthma, which was treated as an effect modifier of the relationships between the outcome and exposure variables.

Multivariable log-binomial and linear regression models were further performed to examine the association between smoking in pregnancy classified in groups and the outcomes of interest after adjusting for confounders. Potential confounders related to the outcomes of interest in the bivariate models with a p-value $<0.2$ were included in the multivariable models. Risk ratios with $95 \%$ confidence intervals $(95 \% \mathrm{CI})$, and coefficients $(\beta)$ with SE were computed to estimate the degree of association. Effect modification was evaluated using the likelihood ratio test and stratified models were obtained. All association testing was conducted assuming a 0.05 significance level and a two-sided alternative hypothesis. Data analysis was performed using STATA version 10.0 (StataCorp LP, College Station, TX, USA).

\section{RESULTS}

$35 \%$ of females reported not being exposed to SHS or active smoking and $\sim 17 \%$ were active smokers while $5 \%$ reported not actively smoking but had a cotinine level of $>50 \mathrm{ng} \cdot \mathrm{mL}^{-1}$. Median birth weight ranged from 3,320 and 3,325 $\mathrm{g}$ among non-SHS and SHS outside the females to 3,130 $\mathrm{g}$ among smoking females (table 1). A similar gradient was also observed for SGA and FwGR. Unadjusted differences between the SHS groups were very small. Birth length, head circumference and gestational age were very similar among the groups. Differences for FlGR and FhcGR were also very small (data not shown). Less than half of the mothers not reporting SHS at home had quantifiable levels. Although differences between SHS groups were small, females exposed at home showed a higher proportion of quantifiable levels and higher levels of cotinine. Cotinine levels were much higher among active smokers. Smoking before pregnancy was very common and increased according to the exposure groups. Few females quit smoking after first trimester of pregnancy. Maternal asthma had a very similar frequency in all exposure groups. If anything, non SHS-exposed females had the lowest prevalence of asthma. Among the rest of variables, the gradient on education and social class by SHS at home and smoking exposure was considered noteworthy.

There was a consistent decrease in birth weight and increase in risk of SGA and FwGR with increasing levels of cotinine (table 2). Birth weight decreased by $\sim 21 \mathrm{~g}$ for the group with

TABLE 1 Birth outcomes, urine cotinine levels, maternal asthma and co-variables by smoking and second-hand smoke (SHS) ${ }^{\#}$ exposure in the INMA cohort

\begin{tabular}{|c|c|c|c|c|c|}
\hline & No SHS & $\begin{array}{l}\text { SHS only outside } \\
\text { the home }\end{array}$ & $\begin{array}{l}\text { SHS inside } \\
\text { the home }\end{array}$ & $\begin{array}{l}\text { No smoking but cotinine } \\
\quad>50 \mathrm{ng} \cdot \mathrm{mL}^{-1}\end{array}$ & Smoking" \\
\hline Subjects n (\%) & $781(35.2)$ & $533(24.0)$ & $445(19.2)$ & $109(4.9)$ & $371(16.7)$ \\
\hline Birth weight $\mathbf{g}$ & $3000 / 3320 / 3575$ & $3050 / 3325 / 3600$ & $3000 / 3300 / 3600$ & $2950 / 3220 / 3450$ & $2850 / 3130 / 3400$ \\
\hline SGA & 7.8 & 7.2 & 10.9 & 13.0 & 16.3 \\
\hline FwGR & 8.3 & 7.7 & 8.3 & 10.2 & 17.1 \\
\hline Birth length $\mathrm{cm}$ & $48.2 / 49.9 / 51$ & $48.5 / 50 / 51$ & $48.9 / 50 / 51$ & $48.8 / 50 / 51$ & $48 / 49 / 50.4$ \\
\hline Birth head circumference $\mathrm{cm}$ & $33.5 / 34.5 / 35.5$ & $33.6 / 34.5 / 35.4$ & $33.5 / 34.5 / 35$ & $33 / 34 / 35$ & $33 / 34 / 35$ \\
\hline Gestational age weeks & $38.8 / 39.9 / 40.6$ & 39/39.9/40.9 & $38.8 / 39.9 / 40.7$ & $38.9 / 39.7 / 40.7$ & $38.7 / 39.7 / 40.6$ \\
\hline Males & 51.5 & 52.5 & 49.2 & 58.7 & 53.9 \\
\hline Cotinine $\geqslant 4 \mathrm{ng} \cdot \mathrm{mL}^{-1}$ & 36.0 & 48.78 & 75.1 & 100 & 100 \\
\hline Cotinine $\mathrm{ng} \cdot \mathrm{mL}^{-1+}$ & $5.9 / 9.0 / 15.5$ & $6.7 / 11.4 / 20.2$ & $9.6 / 17.8 / 28.6$ & $260.7 / 680.6 / 422.8$ & $988.3 / 1864.7 / 2975.7$ \\
\hline Smoking before pregnancy & 37.8 & 44.3 & 52.0 & 82.6 & 100.0 \\
\hline Smoking at week 12 & 0.5 & 1.3 & 1.9 & 9.3 & 100.0 \\
\hline Mean maternal age yrs & 32.6 & 31.9 & 31.3 & 30.7 & 31.2 \\
\hline Maternal asthma & 6.5 & 7.3 & 8.5 & 7.4 & 7.6 \\
\hline Higher education & 42.9 & 47.5 & 24.2 & 24.8 & 12.7 \\
\hline Manual social class & 45.1 & 43.6 & 62.2 & 56.1 & 69.5 \\
\hline Maternal BMI pre-pregnancy & $20.8 / 22.5 / 24.9$ & $20.9 / 22.9 / 25.4$ & $20.3 / 22.2 / 25$ & $21.3 / 22.9 / 25.8$ & $20.9 / 23 / 25.9$ \\
\hline Nullipara & 51.8 & 58.0 & 63.4 & 56.0 & 59.0 \\
\hline
\end{tabular}

Data are presented as 25th/50th/75th percentile or \%, unless otherwise stated. SGA: small for gestational age; FwGR: fetal growth restriction; BMI: body mass index \# : reported passive smoking among females reporting no smoking history and with cotinine levels $<50 \mathrm{mg} \cdot \mathrm{mL}^{-1}$; ${ }^{\bullet}$ reported smoking at week $32 ;{ }^{+}$: if cotinine $\geqslant 4$ ng $\cdot \mathrm{mL}^{-1}$. 


\begin{tabular}{|c|c|c|c|c|c|}
\hline \multirow[t]{3}{*}{ TABLE 2} & \multicolumn{5}{|c|}{$\begin{array}{l}\text { Adjusted associations between birth weight and small for gestational age (SGA), and urine cotinine levels and maternal } \\
\text { second-hand smoke (SHS) exposure in the INMA cohort }\end{array}$} \\
\hline & & \multirow[t]{2}{*}{ Subjects $n$} & \multirow{2}{*}{$\begin{array}{c}\text { Birth weight }{ }^{\#} \\
\text { Coefficient }(95 \% \mathrm{Cl})\end{array}$} & \multicolumn{2}{|c|}{ SGA } \\
\hline & & & & n (\%) & RR (95\% Cl) \\
\hline \multicolumn{6}{|c|}{ Cotinine $\mathrm{ng} \cdot \mathrm{mL}^{-1}$} \\
\hline $20-50$ & & 236 & $-20.99(-75.28-33.30)$ & $25(10.6)$ & $1.21(0.78-1.87)$ \\
\hline$>50$ & & 475 & $-143.67(-186.93--100.41)$ & $73(15.5)$ & $1.80(1.30-2.47)$ \\
\hline \multicolumn{6}{|c|}{ SHS exposure $^{+}$} \\
\hline No & & 781 & $1.09(-43.98-46.17)$ & $60(7.8)$ & $0.82(0.56-1.19)$ \\
\hline Only outsic & the home & 533 & $-0.74(-49.08-47.60)$ & $38(7.2)$ & $0.73(0.48-1.11)$ \\
\hline
\end{tabular}

RR: relative risk; ref: reference. ${ }^{\#}$ : adjusted for sex (ref: male) and gestational age (centred to 40 weeks), maternal asthma, education (ref: university), social class (ref: non-manual,), parity (ref: nulliparous), and height, weight and age (all centred to mean). ": adjusted for maternal education (ref: university), social class (ref: non-manual, only available for INMA cohort), parity (ref: nulliparous), and height, weight and age (all centred to mean). ${ }^{+}$: if cotinine $<50 \mathrm{ng} \cdot \mathrm{mL}^{-1}$ or not reporting active $\mathrm{smoking}$.

cotinine levels between 20 and $50 \mathrm{ng} \cdot \mathrm{mL}^{-1}$. Increases in the risk of SGA and FwGR in this group were very small (RR 1.21 and 1.10 , respectively) and nonsignificant. Only for those with cotinine levels $>50 \mathrm{ng} \cdot \mathrm{mL}^{-1}$ was there a significant decrease in birth weight and increase in risk of SGA and FwGR (RR 1.76). The decrease in birth weight for those reporting SHS at home was very small (table 2), and the risk on SGA and FwGR was nonsignificant.

Stratification by maternal asthma status did not modify the effect of cotinine levels $>50 \mathrm{ng} \cdot \mathrm{mL}^{-1}$ on birth weight, SGA or FwGR and there was no clear pattern of stronger effects among females with asthma (table 3). Similarly, SHS showed a very weak effect on birth weight decrease, which was unmodified by maternal asthma. No effects were seen for length or head circumference in any of the maternal asthma strata.

\section{DISCUSSION}

Maternal asthma, based on self-reported diagnosis by a doctor, did not modify the reproductive effects of smoking. A clear and important effect of having levels of cotinine $>50 \mathrm{ng} \cdot \mathrm{mL}^{-1}$ was found on birth weight, SGA and FwGR. At levels between 20 and $50 \mathrm{ng} \cdot \mathrm{mL}^{-1}$ the decrease on birth weight was $32 \mathrm{~g}$ among those without maternal asthma. Among non-smoking females, reporting SHS at home was not related with lower birth weight. Finally, no effects were seen for length or head circumference.

Females with asthma smoke with the same frequency as nonasthmatics, and asthma did not promote the role of smoking (if anything, impairment of reproductive outcomes was lower among asthmatics), which coincides with the findings of a recent study of a large population of asthmatic mothers [12]. It is important to note that the females in our study were selected from the general population (i.e. upon presentation for the first ultrasound during pregnancy) and asthma may refer to a mild form. This suggests that the mechanisms operating between asthma and tobacco and impaired prenatal growth are independent. Nicotine exposure during pregnancy may increase energy expenditure in the developing fetus through actions on hypothalamic systems, resulting in lower birth weights and body fat levels and changes in cortisol and/or insulin levels suggesting effects on the neuronal systems involved in body weight management.

Unexpectedly, differences on birth weight at lower levels of cotinine in mothers who denied tobacco consumption were smaller than in other studies. In a study on umbilical cord blood cotinine levels in 175 newborns, there was a mean birth weight deficit of $88 \mathrm{~g}$ in newborns exposed to passive smoke whose fathers smoked $>20$ cigarettes $\cdot$ day $^{-1}$ during maternal pregnancy [20]. In 3,529 pregnant females, based on serum cotinine levels between 2 and $10 \mathrm{ng} \cdot \mathrm{mL}^{-1}$, the infants of SHSexposed nonsmokers averaged $45 \mathrm{~g}$ less in birth weight compared with those of unexposed nonsmokers [7]. In a cohort study conducted in 710 nonsmoking pregnant females, the mean birth weight of infants of SHS-exposed nonsmokers with salivary cotinine levels between 1.8 and $14 \mathrm{ng} \cdot \mathrm{mL}^{-1}$ was $87.3 \mathrm{~g}$ lower than that of infants of females with cotinine levels $\leqslant 0.5 \mathrm{ng} \cdot \mathrm{mL}^{-1}$ [9]. A more recent retrospective study using interview data from the parents of 18,297 children born in the UK in 2000 and 2001 revealed that household SHS exposure reduced adjusted birth weight by $36 \mathrm{~g}$ (95\% CI 5-67 g) compared with infants with no maternal SHS exposure [8]. The low levels of cotinine among those reporting SHS (most of them had levels $<20 \mathrm{ng} \cdot \mathrm{mL}^{-1}$ ), as well as the small difference in cotinine levels between non-SHS and SHS females, could account for the present findings of a difference of only $21 \mathrm{~g}$.

The strengths of the present study include the populationbased, multicentre, prospective design and the large numbers of children with anthropometric measurements at birth, as well as the detailed data on smoking habits during pregnancy. The study used a novel indicator, fetal growth restriction, to define an infant who has not achieved its genetic growth potential in utero on the basis of customised birth weight, length or head circumference CIs. This model allowed us to classify neonates as fetal growth restricted, and to differentiate them from those that are constitutionally small $[14,15]$. The study population 
TABLE 3 Adjusted associations between birth weight and small for gestational age (SGA), and urine cotinine levels and maternal second-hand smoke (SHS) exposure by maternal asthma in the INMA cohort

No maternal asthma

Maternal asthma

p-value

\begin{tabular}{|c|c|}
\hline \multicolumn{2}{|l|}{ Birth weight $^{\#}$} \\
\hline \multicolumn{2}{|l|}{ Cotinine $\mathrm{ng} \cdot \mathrm{mL}^{-1}$} \\
\hline$<4$ & 825 \\
\hline $4-20$ & 574 \\
\hline $20-50$ & 218 \\
\hline$>50$ & 438 \\
\hline \multicolumn{2}{|l|}{ SHS exposure } \\
\hline No & 729 \\
\hline Only outside the home & 494 \\
\hline Inside the home & 389 \\
\hline \multicolumn{2}{|l|}{$\mathrm{SGA}^{+}$} \\
\hline \multicolumn{2}{|l|}{ Cotinine $\mathrm{ng} \cdot \mathrm{mL}^{-1}$} \\
\hline$<4$ & $65(7.9)$ \\
\hline $4-20$ & $44(7.7)$ \\
\hline $20-50$ & $24(11.1$ \\
\hline$>50$ & $69(15.9$ \\
\hline \multicolumn{2}{|l|}{ SHS exposure } \\
\hline No & $56(7.8)$ \\
\hline Only outside the home & $32(6.5)$ \\
\hline Inside the home & $44(11$ \\
\hline
\end{tabular}

Data are presented as $\mathrm{n}$ and coefficient $(95 \% \mathrm{Cl})$ for birth weight, and $\mathrm{n}(\%)$ and relative risk (95\% Cl) for SGA, unless otherwise stated. Ref: reference. ${ }^{\#}$ : adjusted for sex (ref: male) and gestational age (centred to 40 weeks), maternal asthma, education (ref: university), social class (ref: non-manual), parity (ref: nulliparous), and height, weight and age (all centred to mean). ": if cotinine $<50 \mathrm{ng} \cdot \mathrm{mL}^{-1}$ or not reporting active smoking. ${ }^{+}$: adjusted for maternal education (ref: university), social class (ref: nonmanual, only available for INMA cohort), parity (ref: nulliparous), and height, weight and age (all centred to mean).

included females from the follow-up of several birth cohorts, giving us the opportunity to account for the effect of exposures assessed prospectively within the cohorts. We did not observe any substantial differences between the crude and the adjusted models. Thus, it is unlikely that over adjustment affected our findings.

The definition of maternal asthma represents the major limitation to this study. This definition was based on diagnosed asthma, the sensitivity of which is most likely low, in contrast to its high specificity. However, this issue probably did not influence the lack of effect modification by maternal asthma since the inclusion of females with symptoms but with nondiagnosed asthma would, if anything, have caused the potential interaction effect of asthma to be diluted. Another limitation in studies on SHS is the misreporting of active smoking. There could be large disparities between reported and true levels of smoking that may result in misclassification of exposure [21]. If the urine sample was taken before smoking the first cigarette of the day (e.g. during the morning), cotinine concentrations may have been reduced, particularly given that the lifetime of cotinine in pregnant females is shorter [22]. However, the maternal visits were always conducted at the same time. Furthermore, the fact that cotinine only indicates recent exposure could result in a residual margin of misclassification between self-reporting and the biomarker. Therefore, we selected the most sensitive cut-off of cotinine levels for active smoking to minimise this error. In any case, relaxation of this cut-off to $100 \mathrm{ng} \cdot \mathrm{mL}^{-1}$ instead of $50 \mathrm{ng} \cdot \mathrm{mL}^{-1}$ resulted in the same results (data not shown), which suggest that the lack of effects at cotinine levels below the "active smoking" cut-off is not an issue. Because we examined only urine cotinine, we could not draw conclusions about the relationship between birth weight and serum or salivary cotinine concentrations on the potential additive effects of biotoxicants associated with cigarette smoking, such as carbon monoxide or thiocyanates, even though urinary cotinine levels have generally shown good agreement with other such biomarkers [23].

We collected maternal urine during the third trimester of pregnancy. However, the gestational age at which a fetus is exposed to the constituents of cigarette smoke may influence the degree to which birth outcomes are affected, and the manner in which this occurs [24]. Recent studies suggest that exposure to cigarette smoking during the third trimester delays fetal growth to a greater degree than smoking earlier in pregnancy [25]. The reduction in birth weight associated with low cotinine levels close to the time of delivery are probably explained by direct effects on placental blood flow and fetal growth patterns [26].

Asthmatic mothers had similar smoking behaviour to nonasthmatic mothers, and the reproductive effects of smoking were not promoted by having asthma. Furthermore, in a country with high prevalence of smoking and SHS, cotinine levels compatible with no active smoking during the third trimester of pregnancy were poorly related to lower birth weight or impaired reproductive outcomes. Cotinine levels 
above the lowest threshold of active smoking were strongly related to reproductive outcomes.

\section{SUPPORT STATEMENT}

This study was funded by grants from the Spanish Ministry of Health, Instituto de Salud Carlos III (Red INMA G03/176, CB06/02/0041, FISPI041436, FIS-PI081151, FIS-PI042018, FIS-PI09/02311, FIS-PI06/0867, FIS-PS09/00090, FIS-FEDER 03/1615, 04/1509, 04/1112, 04/1931, 05/ 1079, 05/1052, 06/1213, 07/0314, and 09/02647), the Generalitat de Catalunya (CIRIT 1999SGR 00241), the Conselleria de Sanitat Generalitat Valenciana, the Universidad de Oviedo, Obra social Cajastur, the Department of Health of the Basque Government (2005111093 and 2009111069), the Provincial Government of Gipuzkoa (DFG06/004 and DFG08/001) and the Fundación Roger Torné.

\section{STATEMENT OF INTEREST}

None declared.

\section{ACKNOWLEDGEMENTS}

The authors would particularly like to thank all the participants for their generous cooperation. A full list of the INMA project investigators is available at www.proyectoinma.org/presentacion-inma/listadoinvestigadores

\section{REFERENCES}

1 Martínez-Sánchez JM, Fernández E, Fu M, et al. Smoking behaviour, involuntary smoking, attitudes towards smoke-free legislations, and tobacco control activities in the European Union. PLoS One 2010; 5: e13881.

2 Villalbí JR. Valoracion de la Ley 28/2005 de medidas sanitarias frente al tabaquismo [Assessment of the Spanish law 28/2005 for smoking prevention]. Rev Esp Salud Publica 2009; 83: 805-820.

3 Hammond SK. Global patterns of nicotine and tobacco consumption. Handb Exp Pharmacol 2009; 192: 3-28.

4 Reeves S, Bernstein IM. Effects of maternal tobacco-smoke exposure on foetal growth and neonatal size. Expert Rev Obstet Gynecol 2008; 3: 719-730.

5 Hegaard HK, Kjaergaard H, Møller LF, et al. The effect of environmental tobacco smoke during pregnancy on birthweight. Acta Obstet Gynecol Scand 2006; 85: 675-681.

6 Kharrazi M, DeLorenze GN, Kaufman FL, et al. Environmental tobacco smoke and pregnancy outcome. Epidemiology 2004; 15: 660-670.

7 Eskenazi B, Prehn AW, Christianson RE. Passive and active maternal smoking as measured by serum cotinine: the effect on birthweight. Am J Public Health 1995; 85: 395-398.

8 Ward C, Lewis S, Coleman T. Prevalence of maternal smoking and environmental tobacco smoke exposure during pregnancy and impact on birth weight: retrospective study using Millennium Cohort. BMC Public Health 2007; 7: 81-86.

9 Rebagliato M, Florey Cdu V, Boldmar F. Exposure to environmental tobacco smoke in nonsmoking pregnant women in relation to birthweight. Am J Epidemiol 1995; 142: 531-537.

10 Breton $\mathrm{MC}$, Beauchesne MF, Lemière $\mathrm{C}$, et al. Risk of perinatal mortality associated with asthma during pregnancy. Thorax 2009; 64: 101-106.
11 Firoozi F, Lemière C, Ducharme FM, et al. Effect of maternal moderate to severe asthma on perinatal outcomes. Respir Med 2010; 104: 1278-1287.

12 Newman RB, Momirova V, Dombowski MP, et al. The effect of active and passive household cigarette smoke exposure on pregnant women with asthma. Chest 2010; 137: 601-608.

13 Guxens M, Ballester F, Espada M, et al. Cohort Profile: The INMAINfancia y Medio Ambiente - (Environment and Childhood) Project. Int J Epidemiol 2011; [Epub ahead of print DOI: 10.1093/ ije/dyr054].

14 Westerway SC, Davison A, Cowell S. Ultrasonic foetal measurements: new Australian standards for the new millennium. Aust $N$ Z J Obstet Gynaecol 2000; 40: 297-302.

15 Mamelle N, Cochet V, Claris O. Definition of foetal growth restriction according to constitutional growth potential. Biol Neonate 2001; 80: 277-285.

16 Blair EM, Liu Y, de Klerk NH, et al. Optimal foetal growth for the Caucasian singleton and assessment of appropriateness of foetal growth: an analysis of a total population perinatal database. $B M C$ Pediatr 2005; 5: 13.

17 National Institute of Standards and Technology. Tobacco Documents Online. Report of Analysis. EPA/NIST Reference Material 8444. Cotinine in Freeze-Dried Human Urine. Tobacco Documents Online. 1993. Available from: http://tobaccodocuments.org/rjr/ 508669038-9043.html

18 Zielińska-Danch W, Wardas W, Sobczak A, et al. Estimation of urinary cotinine cut-off points distinguishing non-smokers, passive and active smokers. Biomarkers 2007; 12: 484-496.

19 Domingo-Salvany A, Regidor E, Alonso J, et al. Una propuesta de medida de la clase social. Grupo de Trabajo de la Sociedad Espanola de Epidemiologia y de la Sociedad Espanola de Medicina de Familia y Comunitaria [Proposal for a social class measure. Working Group of the Spanish Society of Epidemiology and the Spanish Society of Family and Community Medicine]. Aten Primaria 2000; 25: 350-363.

20 Martinez FD, Wright AL, Taussig LM. The effect of paternal smoking on birthweight of newborns whose mothers did not smoke. Am J Public Health 1994; 84: 1489-1491.

21 George L, Granath F, Johansson AL, et al. Self-reported nicotine exposure and plasma levels of cotinine in early and late pregnancy. Acta Obstet Gynecol Scand 2006; 85: 1331-1337.

22 Dempsey D, Jacob P 3rd, Benowitz NL. Accelerated metabolism of nicotine and cotinine in pregnant smokers. J Pharmacol Exp Ther 2002; 301: 594-598.

23 Vardavas CI, Tzatzarakis MN, Tsatsakis AM, et al. Biomarkers of passive smoking among Greek preschool children. Eur J Pediatr 2006; 165: 891-896.

24 Bernstein IM, Mongeon JA, Badger GJ, et al. Maternal smoking and its association with birthweight. Obstet Gynecol 2005; 106: 986-991.

25 El-Mohandes AA, Kiely M, Gantz MG, et al. Prediction of birth weight by cotinine levels during pregnancy in a population of black smokers. Pediatrics 2009; 124: e671-e680.

26 Kalinka J, Hanke W, Sobala W. Impact of prenatal tobacco smoke exposure, as measured by midgestation serum cotinine levels, on foetal biometry and umbilical flow velocity waveforms. Am J Perinatol 2005; 22: 41-47. 